\title{
¿Cómo perciben los estudiantes a sus docentes en la UNAM?
}

\author{
Alma Rocío Hernández Guzmán y Carlos Alberto Jaimes Vergara
}

\section{Resumen}

En aras de reconocer, dialogar y dar lugar a la reflexión sobre la importancia de ser docente en la Universidad Nacional Autónoma de México (UNAM), se realizó un video testimonial que muestra la percepción que tienen de sus profesores y su práctica, los alumnos universitarios, desde bachillerato hasta posgrado.

Este video nos permitió conocer cómo los alumnos ven a sus profesores y profesoras, y hacia dónde les gustaría que dirigieran su práctica docente, adaptándose al contexto propio de cada generación y lo que esto implica. Características como competencia, entrega, honestidad y profesionalismo, así como los valores humanismo, felicidad y pasión en los profesores de la unAm están presentes en mayoría de los alumnos entrevistados. Lo anterior, sin duda, ha dejado huellas positivas en cada uno de ellos tanto en el ámbito profesional como en el personal.

Palabras clave: profesores, alumnos, percepción, práctica docente, unam.

\section{HOW DO STUDENTS PERCEIVE THEIR TEACHERS AT UNAM?}

\section{Abstract}

In order to acknowledge, engage in dialogue, and promote reflection about the importance of being a National Autonomous University of Mexico (UNAM) teacher, we present a testimonial video that shows student's perception, from high school to postgraduate studies, about their teachers and their practice.

This video allowed us to know how students value their teachers, and in what direction would they like them to take their practice, in accordance to each generation context and what it implies. Certain characteristics like competence, commitment, honesty and professionalism, as well as values like humanism, happiness and passion are present among unAm teachers, according to most students. This, no doubt, has left a positive mark in each teacher in both the professional and the personal sphere.

Keywords: teachers, students, percepción, práctica docente, unAm.

Dol: http://doi.org/10.22201/codeic.16076079e.2019.v20n6.a9 


\section{Alma Rocío Hernández Guzmán}

Licenciada en Pedagogía por la Facultad de Filosofía y Letras de la Universidad Nacional Autónoma de México (UnAm). Actualmente se encuentra cursando la Maestría en Administración de la Tecnología en el posgrado que coordina la Facultad de Contaduría y Administración de la unam.

En el 2009 inició su desarrollo profesional en el proyecto SABER-UNAM. En él colaboró como monitora en el desarrollo de bancos de reactivos y como diseñadora instruccional para el desarrollo de Recursos Didácticos Interactivos haciendo uso de las Tecnologías de la Información y la Comunicación (тıc). Actualmente es Jefa de Departamento de Desarrollo Académico de la Coordinación de Desarrollo Educativo e Innovación Curricular (CODEIC) de la unAm y forma parte del equipo del Laboratorio de Desarrollo de Contenidos de dicha coordinación en donde se desempeña como diseñadora instruccional.

\section{Carlos Alberto Jaimes Vergara}

cjaimes vergara@hotmail.com

Ingeniero en Computación por la UnAM, Microsoft Certified Professional, Microsoft Certified Technology Specialist. Net Framework 4, Windows Applications y Oracle Certified Professional Java SE 6 Programmer. Diplomado por la unAm en Planeación y construcción de sitios web, Diplomado por el ITESM en Ingeniería de software, Base de datos y aplicaciones de negocio, Aplicaciones móviles y aplicaciones de negocio y Seguridad informática. Diplomado por 3DMX Digital Design University en Diseño 3D y animación digital. Cuenta con un Nano Degree en Realidad Virtual por parte de Udacity; ha tomado múltiples cursos de desarrollo de videojuegos con diversas tecnologías incluyendo Unity 3D; asimismo, cuenta con una especialidad en Simuladores gráficos por la Universidad Panamericana.

Es Coordinador de diseminación educativa e integración a cargo del Laboratorio de desarrollo de contenidos en la coDeic de la UNAM, en donde se ha dedicado los últimos años al desarrollo de recursos interactivos para la educación. Actualmente está cursando la Maestría en Ingeniería con especialidad en Gestión de proyectos en la Universidad Panamericana. 


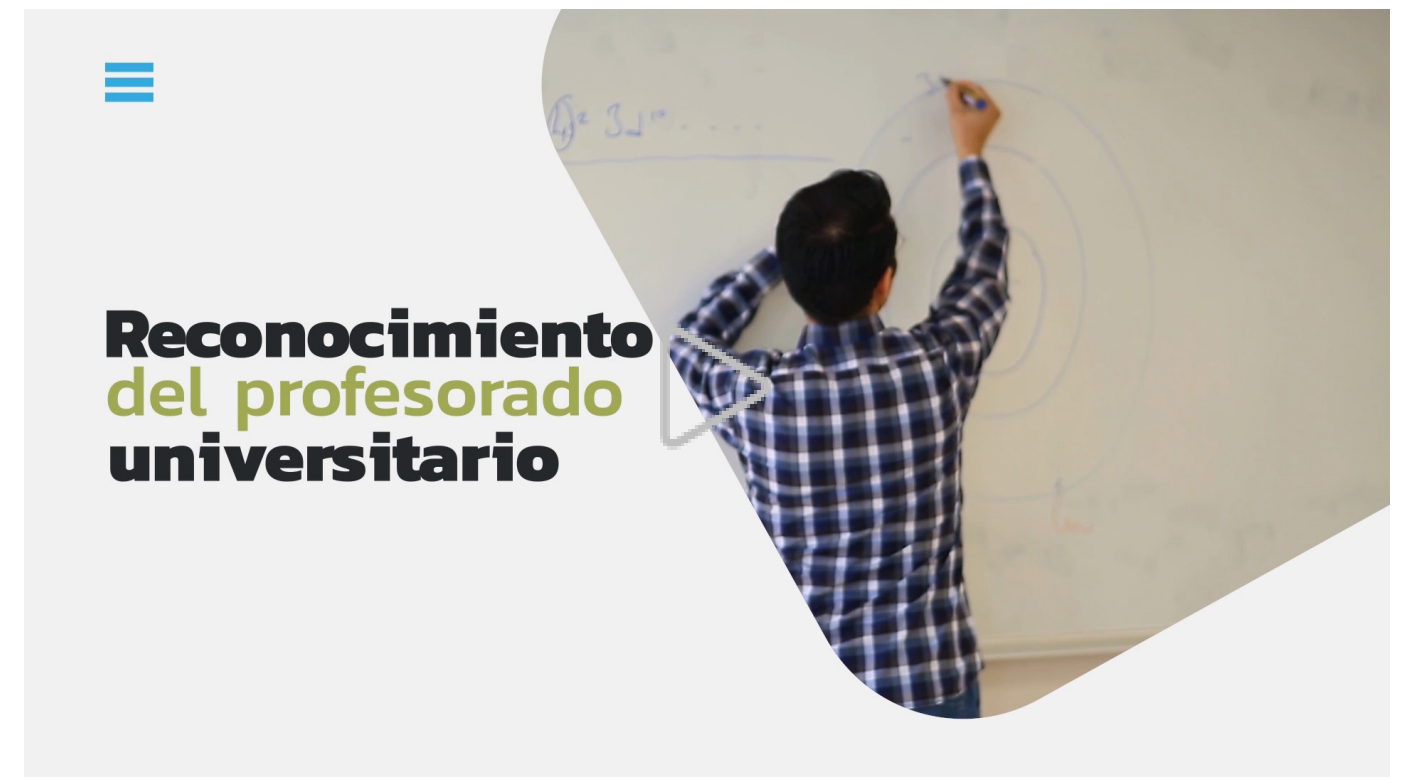

\section{Cómo citar este artículo}

* Hernández Guzmán, Alma Rocío y Jaimes Vergara, Carlos Alberto (2019). ¿Cómo perciben los estudiantes a sus docentes en la UnAm? Revista Digital Universitaria (RDU). Vol. 20, núm. 6 noviembre-diciembre. Dol: http://doi.org/10.22201/ codeic.16076079e.2019.v20n6.a9. 